\title{
Monitoring positive mental health and its determinants in Canada: the development of the Positive Mental Health Surveillance Indicator Framework
}

\section{H. Orpana, PhD (1,2); J. Vachon, MSc (1); J. Dykxhoorn, MSc (1,3); L. McRae, BSc (1); G. Jayaraman, PhD (1,3)}

This article has been peer reviewed.

\section{Abstract}

Introduction: The Mental Health Strategy for Canada identified a need to enhance the collection of data on mental health in Canada. While surveillance systems on mental illness have been established, a data gap for monitoring positive mental health and its determinants was identified. The goal of this project was to develop a Positive Mental Health Surveillance Indicator Framework, to provide a picture of the state of positive mental health and its determinants in Canada. Data from this surveillance framework will be used to inform programs and policies to improve the mental health of Canadians.

Methods: A literature review and environmental scan were conducted to provide the theoretical base for the framework, and to identify potential positive mental health outcomes and risk and protective factors. The Public Health Agency of Canada's definition of positive mental health was adopted as the conceptual basis for the outcomes of this framework. After identifying a comprehensive list of risk and protective factors, mental health experts, other governmental partners and non-governmental stakeholders were consulted to prioritize these indicators. Subsequently, these groups were consulted to identify the most promising measurement approaches for each indicator.

Results: A conceptual framework for surveillance of positive mental health and its determinants has been developed to contain 5 outcome indicators and 25 determinant indicators organized within 4 domains at the individual, family, community and societal level. This indicator framework addresses a data gap identified in Canada's strategy for mental health and will be used to inform programs and policies to improve the mental health status of Canadians throughout the life course.

Keywords: health status indicators, mental health

\section{Introduction}

The Public Health Agency of Canada (the Agency) defines mental health as "the capacity of each and all of us to feel, think, and act in ways that enhance our ability to enjoy life and deal with the challenges we face. It is a positive sense of emotional and spiritual well-being that respects the importance of culture, equity, social justice, interconnections and personal dignity.",
Similarly, the World Health Organization (WHO) defines mental health as "a state of well-being in which every individual realizes his or her own potential, can cope with the normal stresses of life, can work productively and fruitfully, and is able to make a contribution to her or his community." 2 The positive dimension of mental health is emphasized in the definition of health in the WHO constitution: "Health is a state of complete physical, mental and
Key findings

- The Public Health Agency of Canada developed a conceptual framework for the surveillance of positive mental health and its determinants in Canada.

- Included in 4 ecological levelsindividual, family, community and society-were 5 outcomes and 25 determinant indicators.

- The framework provides a structure for positive mental health surveillance data that will inform mental health promotion programs and policies across the life course.

- The framework addresses a key data gap identified in Canada's strategy for mental health Changing Directions, Changing Lives.

social well-being and not merely the absence of disease or infirmity."2

Public health surveillance, one of six core public health functions, ${ }^{3}$ is defined as "the continuous, systematic collection, analysis and interpretation of health-related data needed for the planning, implementation and evaluation of public health practice."4 The Agency's surveillance programs monitor and report on a range of topics related to chronic disease, injury and health behaviours, including mental illness and suicide, in the Canadian population. Canada's national mental health strategy, Changing Directions, Changing Lives, ${ }^{5}$ recommended "strengthen[ing] data and research to develop a better understanding of the mental health

Author references:

1. Surveillance and Epidemiology Division, Centre for Chronic Disease Prevention, Public Health Agency of Canada, Ottawa, Ontario, Canada

2. School of Psychology, University of Ottawa, Ottawa, Ontario, Canada

3. School of Epidemiology and Community Medicine, University of Ottawa, Ottawa, Ontario, Canada

Correspondence: Heather Orpana, Public Health Agency of Canada, 785 Carling Avenue, Office 523B1, Ottawa, ON K1A 0K9; Tel: 613-878-5011; Fax: 613-941-9502;

Email: heather.orpana@phac-aspc.gc.ca 
needs and strengths of diverse population groups" "581 and "improv[ing] mental health data collection, research, and knowledge exchange across Canada." ${ }^{5 p 114}$ As part of the 2013 federal budget, the Government of Canada directed that $\$ 2$ million be reallocated each year for three years to enhance data on mental health, improve knowledge and foster collaboration. While the Agency has an established mental illness surveillance system, ${ }^{6}$ there was no surveillance system focussing on the positive mental health of Canadians in 2013. To address this gap, and in consultation with key stakeholders and experts, the Agency set out to develop a conceptual framework and a core set of indicators for its surveillance of positive mental health and its determinants. The indicators will be used to inform programs and policies to improve the mental health status of Canadians throughout their life course. Although public health professionals as well as policy and program developers and decision makers are the primary audience, we anticipate that the public will be interested because of the increasing attention paid to positive mental health and well-being.

In this paper, we describe the process undertaken by the Agency to establish a Positive Mental Health Surveillance Indicator Framework as well as the rationale for and the principles underlying this project and the progress to date. This includes the conceptual framework and the core indicators for surveillance purposes.

\section{Conceptual framework}

To identify existing mental health surveillance frameworks, a librarian conducted a literature search using Embase (1974 to 2013), Medline (1946 to 2013) and PsycINFO using the following keywords and their combinations: mental health, mental disorders, indicators, criteria, method, measure, policy, policies, develop, surveillance, taxonomy, framework, performance, health status indicators, quality indicators and health care. Results were limited to French and English articles, and articles that were clinically oriented or focussed on a particular patient population were excluded. Altogether, 88 unique articles were identified for review.
An additional Internet search used Google and the keywords mental health, surveillance, and framework.

Components of existing surveillance frameworks were identified, for example, in Waddell et al., ${ }^{7}$ Parkinson $^{8}$ and Korkeila et al. ${ }^{9}$ although there were no frameworks that focussed exclusively on positive mental health and most of the surveillance frameworks were strongly oriented towards mental illness. In addition, we reviewed population health and health promotion approaches that provided the socioecological organizing structure for the framework. ${ }^{10-12}$

Based on these searches, a conceptual framework, which provided the underlying theoretical foundation for this project, was developed in consultation with Mental Health Commission of Canada (MHCC) experts. This conceptual framework was reviewed by the MHCC Directors and the MHCC's Expert Advisory Council. The framework integrated conceptual elements that were important for describing positive mental health in the population (see Figure 1).

Figure 2 summarizes the steps in the development of the Positive Mental Health Surveillance Indicator Framework.

Four components were integrated into an overarching conceptual framework that provided the base on which indicators were selected.

First, positive mental health was conceptualized as a state of well-being that all individuals, regardless of whether they are experiencing a mental illness, are able to enhance. ${ }^{5}$ The concept of positive mental health applies to everyone and therefore holds promise as a mechanism to positively shift the population distribution of well-being.

Second, risk and protective factors, or determinants of positive mental health, were identified as important components of the framework; these factors are the focus of efforts to intervene and improve population mental health. ${ }^{13}$

Third, a socioecological model representing the domains in which these risk and protective factors exist was embedded in the conceptual framework. ${ }^{8,11}$ These individual, family, community and society domains are shown in Figure 1. Each domain influences the positive mental health of the population and is considered a potential entry point for interventions that promote mental health.

Fourth, the life course was represented in the conceptual framework because risk and protective factors vary and accumulate and experiences in early life may continue to affect positive mental health in later life. ${ }^{14}$ The life course stages identified were childhood (0-11 years), youth (12-17 years) and adulthood ( $\geq 18$ years). While these broad categories are heterogeneous, the decision was made to maintain high-level life course stages, with any further refinements reflected in specific indicators and measures. While all but four indicators are the same in the life course stages, the way these concepts are measured changes according to each stage.

\section{Indicator selection criteria}

Once the conceptual framework was identified, each of the framework domains was populated with selected indicators and measures. Indicators were defined as concepts that could be measured and reported on, while measures operationalized the indicators through survey questions, scales or other methods.

Five selection criteria (relevant, actionable, accurate, feasible and ongoing) were used to prioritize the positive mental health indicators and measures. The definitions adopted for these criteria (see Table 1) are widely used to assess indicators. ${ }^{15}$ We also chose these to align with the selection criteria used for the Chronic Disease Indicator Framework ${ }^{16}$ as well as international indicator frameworks. ${ }^{17-20}$ Relevance and actionability were considered within the context of public health programs and policy; accuracy, feasibility and the ongoing nature of the data were considered in the context of the surveillance programs that would collect these data. These criteria were used to select and prioritize indicators as well as to select measures. 
FIGURE 1

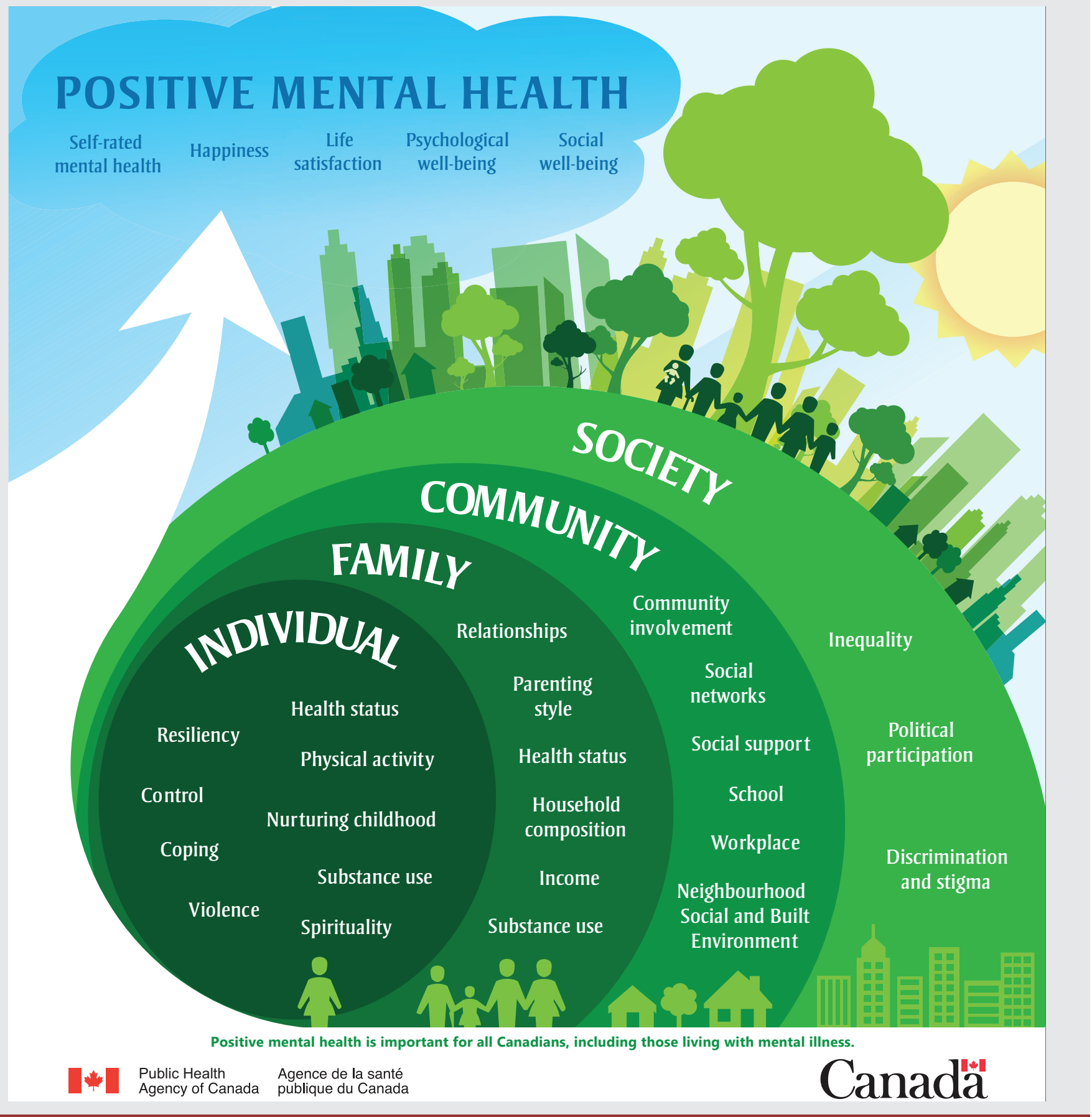

\section{Indicator identification and selection}

We identified a comprehensive list of potential indicators for a positive mental health indicator framework in the retrieved literature (Figure 1). Where needed, we looked up other relevant literature in support of specific content areas, such as positive mental health outcomes.

First, we identified positive mental health outcome indicators based on contemporary positive mental health and wellbeing theory, which generally identifies two components: hedonia, or feeling good, and eudaimonia, or functioning well. ${ }^{21}$ Hedonia is reflected in measures of positive affect and satisfaction with life (emotional well-being), while eudaimonia taps into functioning well, for example, being able to engage in valued activities and have meaningful relationships (psychological and social well-being). ${ }^{22}$ Outcomes 
FIGURE 2

Development process for Positive Mental Health Surveillance Indicator Framework

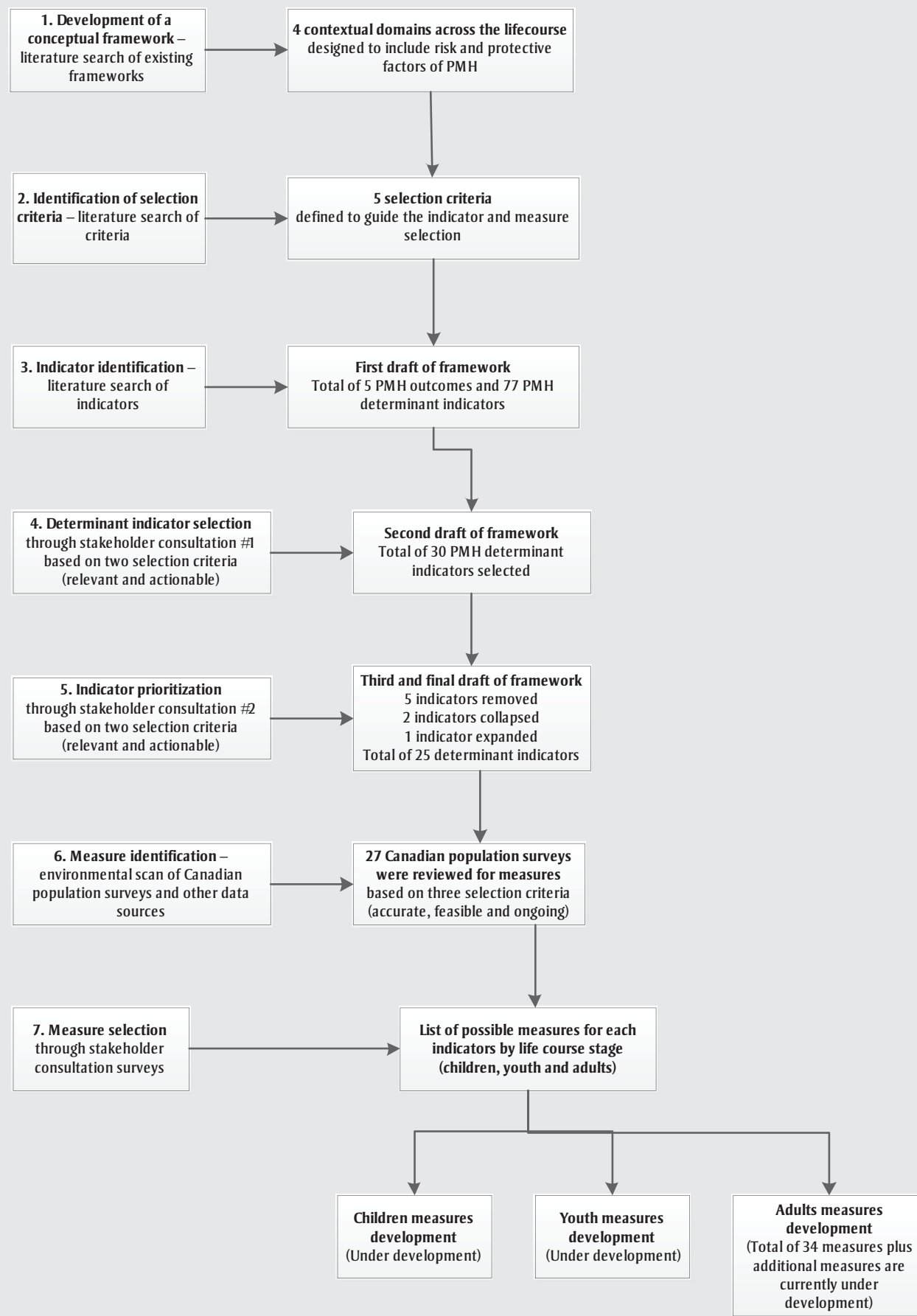

were also chosen to align with the Agency's operational definition of positive mental health. $^{23}$

We then selected positive mental health determinant indicators to capture the risk and protective factors for positive mental health that exist in the individual, family, community and society domains. We identified a number of such indicators in the literature and in other mental health frameworks (for example, Waddell et al., ${ }^{7}$ Parkinson $^{8}$ and Korkeila et al. ${ }^{9}$ ) A thematic synthesis of indicators grouped similar concepts together to streamline the framework and make it more intelligible. We established a clear and concise definition of each indicator as well as an evidence-based rationale establishing the relationship between each determinant and positive mental health.

An initial list of 5 outcome indicators and 77 potential positive mental health determinant indicators was identified (see Table 2). 
TABLE 1

Selection criteria for indicators and measures

\begin{tabular}{ll}
$\begin{array}{l}\text { Selection } \\
\text { criteria }\end{array}$ & \multicolumn{1}{c}{ Description } \\
\hline Relevant & $\begin{array}{l}\text { Provides information that is considered to be meaningful and relevant to the target } \\
\text { user. }{ }^{16-18}\end{array}$ \\
Actionable & $\begin{array}{l}\text { Provides information that can inform, influence, or change public health practice or } \\
\text { policy. }{ }^{16-18}\end{array}$ \\
Accurate & $\begin{array}{l}\text { Reflects the best evidence. It has to be scientifically sound, valid, reliable, sensitive to } \\
\text { change, interpretable and complete. }{ }^{16-18}\end{array}$ \\
Feasible & $\begin{array}{l}\text { Data are available and of sufficient quality to report on or data collection can be put into } \\
\text { place at a relatively low cost. }\end{array}{ }^{16-18}$ \\
Ongoing & Data are collected regularly and trends can be compared over time. ${ }^{16-18}$ \\
\hline
\end{tabular}

Based on previous experiences the Agency had with using a modified Delphi approach to select indicators for the Chronic Disease Indicator Framework ${ }^{16}$ and develop national indicators for osteoporosis in Canada, ${ }^{24}$ we developed an iterative consultation process that would allow a structured approach to indicator selection while taking into account the views and needs of different stakeholder groups. The primary purpose of surveillance data is to inform public health action; for the purposes of the consultation, stakeholders were considered to be public health professionals working in mental health surveillance, programs or policy both internal and external to the Agency.

Two iterative consultation processes were undertaken to reduce the initial list of 77 determinant indicators to a more succinct list.

First, the Mental Health and Mental Illness Surveillance Advisory Committee, a Canadian expert advisory group that advises the Agency on the development, use and evaluation of mental health and mental illness surveillance information, was invited to an in-person meeting in January 2014. This committee includes members from academia, national organizations and provincial/ territorial governments. The committee of 10 was divided into two separate breakout sessions: one group of 5 focussed on indicators in the individual domain, while the other group of 5 focussed on indicators in the family, community and society domains. Both subgroups reviewed the initial list of indicators, discussed the concepts underlying each indicator and provided feedback on reorganizing and prioritizing the indicators. They then reported their findings and decisions to the entire committee. Based on two selection criteria (relevant and actionable), the committee came to a consensus on the primary positive mental health outcomes and the top five determinant indicators in each domain. The indicator list was narrowed to 30 determinant indicators that represented the most relevant and actionable indicators associated with positive mental health.

A second phase of consultation was then conducted with the Mental Health Promotion Task Group, a subgroup of the Healthy People and Communities Steering Committee (HPCSC). HPCSC is one of the three federal/provincial/territorial steering committees that report to the Pan-Canadian Public Health Network Council. ${ }^{25}$ This task group is made up of mental health promotion experts from several provincial and territorial governments as well as representatives from the Agency and the First Nations and Inuit Health Branch of Health Canada.

As with the first phase of consultation, the concepts underlying each indicator and the evidence for the associations between the risk and protective factors and the positive mental health outcomes were discussed. The 11 task group representatives were asked to decide if any of the 30 determinant indicators in the revised list were redundant or if any were missing, and then to prioritize indicators. They were asked to use web-based voting technology to select the 5 (out of 12) most relevant and actionable indicators for the individual domain, 3 (out of 7) for the family domain and 4 (out of 8) for the community domain. (The society domain was not part of the selection as it included only 3 identified indicators.) Each chosen indicator received one vote, and the sum of the votes for each indicator was used to rank them from most to least preferred; this ranking was presented back to the task group for validation.

This selection process led to 5 indicators ("Tobacco Use," "Problem Gambling," "Teenage Parents," "Caregiving for a Family Member" and "Participation and Volunteering") being removed from the list of 30 because they received few votes, resulting in 25 determinant indicators. ("Participation and Volunteering"' were subsequently reincluded as measures under the community involvement indicator in the community domain). On further review, "Resilience and Coping" was separated into 2 indicators for clarity, and 2 other indicators were regrouped into one, "Trust and Neighbourhood Social Environment," as they had significant overlap when we were identifying measures.

This resulted in a total list of 25 determinant indicators across the 4 contextual domains (individual, family, community, society).

See Table 2 for a comparison of the initial and the final list of indicators.

\section{Measures identification and selection}

Once the indicators were selected, we reviewed Canadian population-based surveys to identify measures for each of the indicators. Where relevant, we also reviewed other data sources such as geospatial data. We then assessed the identified measures using three selection criteria (accurate, feasible and ongoing).

Before identifying the measures, we assessed the indicators for their applicability to different age groups. Recognizing that some are more salient to particular life course stages, we identified separate measures for children (0-11 years), youth (12-17 years) and adults ( $\geq 18$ years). "Nurturing Childhood Experiences," "Parenting Style" and "School Environment" 
TABLE 2

Initial and final list of positive mental health surveillance indicators

\begin{tabular}{|c|c|}
\hline Initial list of possible indicators & Final list of indicators \\
\hline \multicolumn{2}{|l|}{ A. POSITIVE MENTAL HEALTH OUTCOMES } \\
\hline $\begin{array}{l}\text { 1.1. Hedonic well-being } \\
\text { a. Subjective well-being } \\
\text { b. Happiness (positive emotions) } \\
\text { c. Life satisfaction } \\
\text { d. Emotional well-being }\end{array}$ & $\begin{array}{l}\text { 1. Self-rated mental health } \\
\text { 2. Happiness } \\
\text { 3. Life satisfaction }\end{array}$ \\
\hline $\begin{array}{l}\text { 1.2. Eudaimonic well-being } \\
\text { a. Psychological well-being }\end{array}$ & $\begin{array}{l}\text { 4. Psychological well-being } \\
\text { 5. Social well-being }\end{array}$ \\
\hline \multicolumn{2}{|l|}{$\begin{array}{l}\text { B. RISK AND PROTECTIVE FACTORS } \\
\text { 1. INDIVIDUAL }\end{array}$} \\
\hline $\begin{array}{l}\text { 1.1. General health } \\
\text { a. Self-rated health } \\
\text { b. Self-rated mental health } \\
\text { c. Presence of chronic conditions }\end{array}$ & $\begin{array}{l}\text { 6. Health status } \\
\text { (Self-rated mental health under Outcomes) }\end{array}$ \\
\hline $\begin{array}{l}\text { 1.2. Personal health practices } \\
\text { a. Healthy living/personal health practices } \\
\text { b. Physical activity } \\
\text { c. Sedentary activity } \\
\text { d. Healthy eating } \\
\text { e. Body mass index }\end{array}$ & 7. Physical activity \\
\hline $\begin{array}{l}\text { 1.3. Addiction and health risk behaviours } \\
\text { a. Tobacco use/smoking } \\
\text { b. Alcohol use/misuse } \\
\text { c. Substance use/misuse } \\
\text { d. Injury prevention practices } \\
\text { e. Sexual risk taking } \\
\text { f. Problem gambling }\end{array}$ & 8. Substance use (Alcohol and Drugss) \\
\hline $\begin{array}{l}\text { 1.4. Growth and development } \\
\text { a. Maternal nutrition } \\
\text { b. Supplemental intake during pregnancy } \\
\text { c. Breastfeeding } \\
\text { d. Alcohol consumption during pregnancy } \\
\text { e. Smoking during pregnancy \& breastfeeding } \\
\text { f. Substance use/misuse during pregnancy } \\
\text { g. Exposure to hazards during childhood }\end{array}$ & 3. Nurturing childhood environment \\
\hline $\begin{array}{l}\text { 1.5. Biology and genetic endowment } \\
\text { a. Biology and genetic endowment }\end{array}$ & \\
\hline $\begin{array}{l}\text { 1.6. Personality } \\
\text { a. Self-esteem } \\
\text { b. Sense of mastery } \\
\text { c. Sense of coherence } \\
\text { d. Optimism/pessimism } \\
\text { e. Emotional intelligence }\end{array}$ & $\begin{array}{l}\text { 1. Resilience } \\
\text { 4. Control and self-efficacy }\end{array}$ \\
\hline $\begin{array}{l}\text { 1.7. Spirituality and religiosity } \\
\text { a. Spirituality } \\
\text { b. Religiosity }\end{array}$ & 9. Spirituality \\
\hline $\begin{array}{l}\text { 1.8. Adverse childhood experiences } \\
\text { a. Adverse childhood experiences }\end{array}$ & \\
\hline $\begin{array}{l}\text { 1.9. Current stressful life } \\
\text { a. Violence (including domestic violence, maltreatment, abuse) } \\
\text { b. Discrimination } \\
\text { c. Financial constraints/debt management }\end{array}$ & $\begin{array}{l}\text { 5. Violence } \\
\text { (Discrimination under Society domain) }\end{array}$ \\
\hline $\begin{array}{l}\text { 1.10. Coping } \\
\text { a. Coping }\end{array}$ & 2. Coping \\
\hline
\end{tabular}

Continued on the following pages 
TABLE 2 (continued)

Initial and final list of positive mental health surveillance indicators

\section{FAMILY}

2.1. Family structure

a. Lone parent

b. Contact with non-resident birth parent

c. Teenage parents

d. Parental imprisonment

2.2. Family relations
a. Family relationship quality and connectedness
b. Family meals
2. Parenting style

1. Family relationships

c. Talking to family

d. Treatment by parent(s)/parenting style

2.3. Family general health
a. Family mental well-being
b. Parental common mental health problems

2.4. Parental health living practices
a. Family addictions

2.5. Caregiving

a. Caregiving for a family member

5. Household composition

\section{COMMUNITY}

3.1. Social capital
a. Social capital

3.2. Social support, social provisions, and social networks
a. Social support and provisions

3. Social support

b. Social networks and social contact

3. Family physical and mental health status

4. Substance use by family members

3.3. Peer and friend relationships

a. Interpersonal relationships

b. Social engagement

3.4. Inclusion and belonging
a. Social inclusion and exclusion
b. Workless households
c. Education
d. Homelessness

3.5. School and work environments
a. School environment and school achievement
b. Workplace characteristics/environment
5. Workplace environment

4. School environment

3.6. Access to and organization of health and social services
a. Access to health services including mental health services

3.7. Participation
a. Participation
b. Volunteering

3.8. Neighbourhood characteristics
a. Neighbourhood characteristics

b. Neighbourhood satisfaction

6. Household income

3.9. Community cohesion
a. Community cohesion
b. Community connectedness

3.10. Trust and safety

a. Neighbourhood safety/crime/violence

b. Perception of safety and crime

(Political participation under Society domain)

1. Community involvement

6. Neighbourhood social environment

7. Neighbourhood built environment

6. Neighbourhood social environment

6. Neighbourhood social environment

Continued on the following page 
TABLE 2 (continued)

Initial and final list of positive mental health surveillance indicators

\begin{tabular}{|c|c|}
\hline 4. SOCIETY & \\
\hline $\begin{array}{l}\text { 4.1. Social justice } \\
\text { a. Social justice }\end{array}$ & \\
\hline $\begin{array}{l}\text { 4.2. Equity/equality } \\
\text { a. Equality analysis } \\
\text { b. Poverty }\end{array}$ & $\begin{array}{l}\text { (Household income under Family domain) } \\
\text { 1. Inequality }\end{array}$ \\
\hline $\begin{array}{l}\text { 4.3. Physical environment (Built and natural environments) } \\
\text { a. Escape facilities } \\
\text { b. Green spaces } \\
\text { c. House condition } \\
\text { d. Overcrowding } \\
\text { e. Noise }\end{array}$ & $\begin{array}{l}\text { (Neighbourhood social environment and } \\
\text { Neighbourhood built environment under } \\
\text { Community domain) }\end{array}$ \\
\hline $\begin{array}{l}\text { 4.4. Politics and Governance } \\
\text { a. Healthy public policy }\end{array}$ & \\
\hline $\begin{array}{l}\text { 4.5. Laws and policies } \\
\text { a. Victimization } \\
\text { b. Discrimination }\end{array}$ & 2. Discrimination \\
\hline \multirow[t]{2}{*}{$\begin{array}{l}\text { 4.6. Culture } \\
\text { a. Culture and values }\end{array}$} & \\
\hline & 3. Political participation \\
\hline
\end{tabular}

were included only in the child and youth frameworks; "Work Environment" was included only in the adult framework. The adult framework has been completed (please contact the authors to receive a copy), while the child and youth measures are currently under development.

Based on the results of the scan of surveys and other data sources, we identified measures and data sources that could potentially be used to report on the selected indicators at the national level in Canada. We included data sources that were no longer active and for which ongoing data would not be available as well as those sources that focussed solely on specific subpopulations only when no other data sources were identified. In addition to reviewing measures available on existing Canadian population surveys, we reviewed other literature to identify alternate measures for a number of indicators, particularly for those for which no ongoing Canadian data sources exist.

We conducted an online consultation to gather expert and stakeholder advice on the best measures to report on the prioritized indicators. The same groups that were consulted earlier were invited to participate, that is, the Mental Health Promotion Task Group and the Mental Health and Mental Illness Surveillance Advisory Committee, as well as
Agency employees in surveillance and mental health promotion. The first phase of the twophase survey-based consultation focussed on positive mental health outcome measures as well as the measures for the determinant indicators in the individual domain. The second phase focussed on the measures for the determinant indicators in the three remaining domains: the family, community and society domains. The surveys presented the measures identified through the environmental scan of surveys and data sources for each of the positive mental health outcome and determinant indicators, by life course stage (child, youth, adult), where applicable. Experts and stakeholders were asked to use accuracy and feasibility as their primary selection criteria for the measures. The ongoing availability of the data was considered ideal but not necessary.

Three types of questions were asked in the consultation surveys:

1) where an existing measure was identified as the only available data for an indicator, participants were asked for comments on the use of this measure for the framework and if they were aware of additional validated scales or measures;

2) when there were multiple possible measures for the same indicator, experts were asked to choose the measure they believed best reflected the given indicator, or to comment on the suitability and availability of the measures; and

3) when measures had not been identified for an indicator, experts were asked to recommend some, and where possible, their corresponding data sources.

Based on the feedback received, we considered the most accurate and feasible measures, and tried, as much as possible, to choose measures from the same data sources. Where no ongoing source was found, we identified measures from onetime surveys or discontinued surveys, for example, the Survey of Young Canadians and the National Longitudinal Survey of Children and Youth, that could be used for an initial round of reporting and as possible content for future surveys. Measures from these sources were flagged as priorities for data development to support future reporting.

If multiple measures were considered to be accurate, feasible and ongoing,

- measures that had national coverage were preferred over those with partial geographic coverage;

- measures from recent surveys were preferred over those from older surveys; 
- measures that fully covered the age range for children, youth or adults were preferred over those with a limited age range; and

- measures that had been psychometrically tested and validated for population surveys were preferred over those where this evidence was not apparent.

If multiple measures met these additional considerations, those from the Canadian Community Health Survey were preferred for adults to facilitate modelling and trend analysis. Similarly, measures from the Health Behaviour in School-Aged Children survey or the Canadian Community Health Survey were preferred for youth over those from other data sources.

During each phase of consultation, additional measures or data sources suggested by stakeholders were reviewed for inclusion in the framework to ensure that it represented the best evidence on positive mental health and its determinants. Data gaps were identified where measures were unavailable or of insufficient quality, and the Agency is proactively collaborating with its partners to identify mechanisms to fill key data gaps.

Two summary reports written by the Agency present the consultation findings to our stakeholders. The first focusses only on the adult framework, while the second reports on the child and youth frameworks.

\section{Conclusions and implications}

The Positive Mental Health Surveillance Indicator Framework forms the foundation on which indicators and measures to report on positive mental health among Canadians are selected. The indicators paint a comprehensive picture of the positive mental health outcomes and associated key determinants for children, youth and adults in Canada. Overall, 5 positive mental health outcomes and 25 related determinant indicators within the individual, family, community and society domains have been selected, and associated measures identified for adults. Psychometric analyses indicate that the proposed approach to reporting on positive mental health outcomes is empirically supported. ${ }^{26}$ Measures are currently being identified for the child and youth frameworks, and data for youth are expected to be ready for release in 2016.

This work supports the promotion of positive mental health as an important public health activity, and the framework fills an important data gap as identified in Canada's mental health strategy. The aim of the framework is to provide a snapshot of positive mental health among Canadians; it has the potential to inform mental health promotion and mental illness prevention programs and policies at multiple levels. Differences in levels of positive mental health may help identify those groups that could benefit from intervention, and the patterns of risk and protective factors will help inform the nature of those interventions. Based on the analysis of historical data, we anticipate being able to observe shifts, over time, in the positive mental health profile of Canadians.

A major success of this work was the focus on a collaborative approach through the development of strong stakeholder relationships. The creation of the framework relied on collaboration and consultation with provincial and territorial governments, nongovernmental organizations, including the MHCC, and researchers. These relationships ensured that the framework was based on stakeholder needs as well as the best evidence about positive mental health, and that the framework would be able to inform research, programming and policy decisions.

Reporting on the indicators and measures is a priority. The first infographic on positive mental health is available at http://www. phac-aspc.gc.ca/mh-sm/mhp-psm/pmh-smpeng.php. The Positive Mental Health Surveillance Indicator Framework Quick Stats, 2016 Adult Edition, are also published in this issue, providing the latest data for positive mental health outcomes, and risk and protective factors. An online Infobase will be available in 2016, allowing users to explore data from the framework by key sociodemographic variables such as age, sex, income and immigrant status. We foresee a continued focus on data development to address data gaps and continued improvement of the selected indicators and measures. Additional work is underway to develop a similar surveillance framework for suicide, including its risk and protective factors, many of which are shared with positive mental health. Future work may lead to more outcomes that reflect Canada's mental health strategy, including mental illness and suicide.

\section{Acknowledgements}

We would like to thank the Mental Health and Mental Illness Surveillance Advisory Committee for their expert advice and feedback on the selection of indicators and measures, Marianna Ofner for leading initial work on the positive mental health conceptual framework development, and the Mental Health Promotion Unit for providing ongoing input in our surveillance work.

\section{References}

1. Public Health Agency of Canada. Mental health promotion: promoting mental health means promoting the best of ourselves [Internet]. Ottawa (ON): Public Health Agency of Canada. [modified 2014 May 6; cited 2015 Sep 26]. Available from: http://www.phac-aspc.gc.ca/ mh-sm/mhp-psm/index-eng.php

2. World Health Organization. Mental health: a state of well-being [Internet]. Geneva (CH): World Health Organization; [updated 2014 Aug; cited 2015 Sep 26]. Available from: http://www.who.int/features/factfiles/ mental_health/en/

3. Public Health Agency of Canada. Evaluation of the surveillance function at the Public Health Agency of Canada [Internet]. Ottawa (ON): Public Health Agency of Canada; [updated 2013 May 14; cited 2015 Sep 26]. Available from: http://www.phac-aspc.gc.ca/ about_apropos/evaluation/reports-rapports/ 2012-2013/sf-fs/section-1-eng.php

4. World Health Organization. Public Health Surveillance [Internet]. Geneva $(\mathrm{CH})$ : World Health Organization; [updated 2015; cited 2015 Sep 26]. Available from: http://www.who.int/ topics/public_health_surveillance/en/

5. Mental Health Commission of Canada. Changing directions, changing lives [Internet]. Calgary $(\mathrm{AB})$ : Mental Health Commission of Canada; 2012 [cited 2015 Sep 26]. Available from: http://strategy.mental healthcommission.ca/pdf/strategy-imagesen.pdf 
6. Public Health Agency of Canada; Mood Disorders Society of Canada; Health Canada; Statistics Canada; Canadian Institute for Health Information. The human face of mental health and mental illness in Canada 2006 [Internet]. Ottawa (ON): Government of Canada; 2006 [updated 2012 Apr 18; cited 2015 Sep 26]. Available from: http://www. phac-aspc.gc.ca/publicat/human-humain06/ index-eng.php

7. Waddell C, Shepherd CA, Chen A, Boyle MH. Creating comprehensive children's mental health indicators for British Columbia. Can J Commun Ment Health. 2013;32(1):9-27.

8. Parkinson J. Establishing national mental health and well-being indicators for Scotland. J Public Mental Health. 2007;5(1):42-8.

9. Korkeila J, Lehtinen V, Bijl R, Dalgard OS, Kovess V, Morgan A, et al. Establishing a set of mental health indicators for Europe. Scand J Public Health. 2003;31(6):451-9.

10. McLeroy KR, Bibeau D, Steckler A, Glanz K. An ecological perspective on health promotion programs. Health Educ Q. 1988; 14(4):351-77.

11. Dahlgren G, Whitehead M. Policies and strategies to promote equity in health. Stockholm (SE): Institute for Futures Studies; 1991.

12. Centers for Disease Control and Prevention. The social-ecological model: a framework for prevention [Internet]. Bethseda (MA): Centers for Disease Control and Prevention; [updated 2015 Mar 25; cited 2015 Sep 26). Available from: http://www.cdc. gov/violenceprevention/overview/socialecologicalmodel.html

13. World Health Organization, Department of Mental Health and Substance Abuse; Victorian Health Promotion Foundation; University of Melbourne. Promoting mental health: concepts, emerging evidence, practice: summary report. Geneva $(\mathrm{CH})$ : World Health Organization; 2004. p. 67.

14. Keating DP, Hertzman C, editors. Developmental health and the wealth of nations: social, biological and educational dynamics. New York (NY): The Guilford Press; 1999. p. 406.
15. Hall HI, Correa A, Yoon PW, Braden CR. Lexicon, definitions, and conceptual framework for public health surveillance. MMWR Surveill Summ. 2012;61(Suppl):10-14.

16. Betancourt MT, Roberts KC, Bennett TL, Driscoll ER, Jayaraman G, Pelletier L. Monitoring chronic diseases in Canada: the Chronic Disease Indicator Framework. Chronic Dis Inj Can. 2014;34(1):1-30.

17. Flowers J, Hall P, Pencheon D. Public health indicators. Public Health. 2005;119(4):239-45.

18. Hermann CR, Leff HS, Lagodmos G. Selecting process measures for quality improvement in mental healthcare. Cambridge (MA): Health Services Research Institute; 2002. Joint publication with Center for Mental Health Services.

19. Australian Institute of Health and Welfare. Key indicators of progress for chronic disease and associated determinants. Canberra (AU): Australian Institute of Health and Welfare; 2009.

20. National Mental Health Performance Subcommittee. Key performance indicators for Australian public mental health services. 2nd ed.)Canberra (AU): Commonwealth of Australia; 2011. p.60.

21. Deci EL, Ryan RM. Hedonia, eudaimonia, and well-being: an introduction. J Happiness Stud. 2008;9(1):1-11.

22. Huppert FA, So TT. Flourishing across Europe: application of a new conceptual framework for defining well-being. Soc Indic Res. 2013; 110(3):837-61

23. Lakaski C, Trottier M. Developing an operational definition of positive mental health. Unpublished final report based on consultation and workshop 2009 Feb 26-27, Conference Centre, Ottawa, Ontario. Located at: Ottawa (ON): Mental Health Promotion Unit; 2009.

24. LeMessurier J, O’Donnell S, Walsh P, McRae L, Bancej C. The development of national indicators for the surveillance of osteoporosis in Canada. Chronic Dis Inj Can. 2012;32(2):101-7.
25. Pan-Canadian Public Health Network. About the Pan-Canadian Public Health Network [Internet]. Ottawa (ON): Pan-Canadian Public Health Network; [modified 2012 Jul 9; cited 2015 Sep 26]. Available from: http://www. phn-rsp.ca/network-eng.php

26. Orpana H, Vachon J, Dykxhoorn J, Jayaraman G. Measuring positive mental health using items from the Mental Health Continuum-Short Form in the Canadian population: a new approach. Internal report. Forthcoming 2015 